\title{
ANALISIS PERKEMBANGAN MORAL DAN SPIRITUAL PADA SANTRI \\ MADRASAH DINIYAH AL-MUTMA'INNAH WINONG JETIS \\ PONOROGO
}

Yuli Umro'atin

Institut Agama Islam Riyadlotul Mujahidin Ngabar (IAIRM) Ponorogo

\begin{abstract}
Keywords: Analysis, Moral and Spiritual Development
\end{abstract}

Studying the development of humans and other creatures in general, we must distinguish two things, namely the process of maturation (maturation means the process of growth which involves perfecting bodily functions so as to cause changes in behavior regardless of the presence or absence of the learning process) and the process learning (learning, means changing or improving behavior through practice, experience and contact with the environment in humans is very important to learn through social contact so that people live in a society with a complex cultural structure).

This research is located at Madrasah Diniyah Al-Mutma'innah Winong Jetis Ponorogo. This research uses a qualitative approach, which is a case study, which examines in depth all the events related to the discussion. The method used in gathering information in the field is the method of observation and in-depth interviews. Analysis of the data used is data reduction, data presentation and conclusions.

From the results of research in the field, it is known that: 1) Moral development of madrasa diniyah al-Mutma'innah students includes: The majority of madrasa santri have behaved well even though not yet $100 \%$, have characteristics or uniqueness of each in terms of moral / behavior, behave politely, respect to the teacher, behave well to the surrounding community, and peers even though it is not yet optimal and need better guidance, have a sense of responsibility towards himself, the teacher and fellow friends, and like to imitate everything they see, observe, and they hear. 2) The spiritual development of children / santri madrasah diniyah al-Mutma'innah is as follows: The students have begun to recognize their true identity as servants of Allah SWT, believe in the existence of God the Creator, Angels, Apostles, and the book of God, know their true identity as students study Islamic religion in madrasa, start practicing worship both in madrasa and in the community / residence, have an enthusiastic attitude and enthusiasm in learning the Koran including tartilnya, memorization and recitation, have a high enthusiasm in learning, creativity, adventure outside and others. 3) Factors that influence students' moral and spiritual development are internal and external factors. 


\section{A. PENDAHULUAN}

Mempelajari perkembangan manusia dan makhluk-makhluk lain pada umumnya, kita harus membedakan dua hal yaitu proses pematangan (pematangan berarti proses pertumbuhan yang menyangkut penyempurnaan fungsi-fungsi tubuh sehingga mengakibatkan perubahan-perubahan dalam tingkah laku terlepas dari ada atau tidak adanya proses belajar) dan proses belajar (belajar, berarti mengubah atau memperbaiki tingkah laku melalui latihan, pengalaman dan kontak dengan lingkungan pada manusia penting sekali belajar melalui kontak sosial agar manusia hidup dalam masyarakat dengan struktur kebudayaan yang rumit itu). Selain itu masih ada ketiga yang ikut menentukan kepribadian yaitu kepribadian atau bakat.

Menurut Hartati (2004: 13) perkembangan dapat diartikan sebagai perubahan- perubahan yang dialami oleh individu atau organisme menuju tingkat kedewasaannya atau kematangannya yang berlangsung secara sistematis (saling bergantungan sama lain dan saling mempengaruhi antara bagian- bagian orgasme dan merupakan suatu kesatuan yang utuh). ${ }^{1}$

Di antara amanat Allah yang agung dan indah namun juga berat adalah anak. Banyak orang tua yang bahagia mendapat karunia anak, Saking bahagianya seluruh kasih sayang tercurah kepadanya namun memberikan kasih sayang yang berlebihan dapat membentuk karakter anak yang tidak baik bagi anak. Untuk dapat membentuk karakter baik tentunya perlu dipersiapakan sejak sedini mungkin karena masa usia dini merupakan masa keemasan, pada masa ini anak akan menyerap apa saja yang diberikan kepadanya entah itu dari perkataan dan perbuatan orang tua atau dari lingkungannya. ${ }^{2}$

Pendidikan agama jika diajarkan sejak usia dini akan membawa berkah bagi keluarga tersebut, seperti pada agama Islam diatur segala aspek kehidupan manusia, baik hubungan manusia dengan Tuhannya, manusia dengan diri sendiri, manusia dengan manusia lainnya maupun manusia dengan alam sekitarnya.2

\footnotetext{
${ }^{1}$ eprint.walisongo.ac.id/7074/3/BAB\%2011.pdf.

${ }^{2}$ Siti Nurjanah, Perkembangan Nilai Agama dan Moral (STTPA Tercapai), Jurnal Paramurobi, Vol. 1, No. 1, Januari-Juni 2018.
} 
Berkaitan dengan potensi yang dimiliki anak sejak lahir, hadis yang diriwayatkan Bukhârî dari Abû Hanifah: "Setiap anak yang dilahirkan memiliki fitrah, maka kedua orang tuanya yang menjadikan anak tersebut beragama Yahudi, Nasrani, ataupun Majusi ",3

\section{B. PEMBAHASAN}

\section{Landasan Teori}

a. Perkembangan Moral

1) Pengertian moral

Kata moral berasal dari bahasa latin mos (jamak mores) yang berarti kebiasaan, adat (Bertens, 1993). Moral merupakan suatu standart salah atau benar bagi seseorang (Rogers \& Baron, dalam Martini, 1995). Kata moral sendiri berasal dari bahasa Latin moris yang berarti adat istiadat, kebiasaan, tata cara dalam kehidupan. Jadi suatu tingkah laku dikatakan bermoral apabila tingkah laku itu sesuai dengan nilai - nilai moral yang berlaku dalam kelompok sosial dimana anak itu hidup.

Sejalan dengan pengertian di atas, menurut Hurlock (2003) moral berasal dari bahasa latin "Mores", yang berarti budi bahasa, adat istiadat, dan cara kebiasaan rakyat. Perilaku moral merupakan perilaku di dalam konformitas dengan suatu tata cara moral kelompok sosial. Kohlberg menegasakan bahwa moral merupakan bagian dari penalaran. Maka iapun menamakannya dengan penalaran moral.

\section{2) Penalaran Moral}

Kohlberg (dalam Slavin, 2011) mendefinisikan penalaran moral sebagai penilaian nilai, penilaian sosial, dan juga penilaian terhadap kewajiban yang mengikat individu dalam melakukan suatu tindakan. Penalaran moral dapat dijadikan sebuah prediktor terhadap dilakukannya tindakan tertentu pada situasi yang melibatkan moral. Kohlberg mengemukakan bahwa penalaran moral adalah suatu pemikiran tentang

\footnotetext{
${ }^{3}$ R.A. Anggraini Notosrijoedono, Peran Keluarga Dalam Mengembangkan Kecerdasan Spiritual Anak Usia Dini, MIQOT Vol. XXXVII No. 1 Januari-Juni 2013.
} 
masalah moral. Pemikiran tersebut merupakan prinsip yang dipakai dalam menilai dan melakukan suatu tindakan dalam situasi moral.

Menurut teori Piaget (dalam Slavin, 2011) proses penalaran moral sejalan dengan perkembangan kognisi. Piaget percaya bahwa struktur dan kemampuan kognisi berkembang lebih dulu. Kemampuan kognisi kemudian menentukan kemampuan anak-anak bernalar mengenai dunia sosialnya.

Piaget membagi tahap perkembangan moral menjadi dua, yaitu tahap moralitas heteronom dan tahap moralitas otonom. Tahap moralitas heteronom terjadi pada usia anak-anak awal yaitu sekitar usia 4 tahun hingga 7 tahun. Slavin (2011) menyebutnya juga sebagai tahap "realisme moral" atau "moralitas paksaan". Kata Heteronom berarti tunduk pada aturan yang diberlakukan orang lain. ${ }^{4}$

\section{3) Perkembangan Moral}

Dalam mempelajari perkembangan sikap moral peserta didik usia sekolah, piaget (sinolungun, 1997) mengemukakan tiga tahap perkembangan moral sesuai dengan kajian pada aturan dalam permainan anak. Piaget membagi pekembangan menjadi 3 fase yaitu:

(1) Fase absolut. anak menghayati peraturan sebagai suatu hal yang dapat diubah, karena berasal dari otoritas yang dihormatinya. Disini peraturan sebagai moral adalah obyek eksternal yang tidak boleh diubah. (2) Fase realitas anak menyesuaikan diri untuk menghindari penolakan orang lain. Peraturan dianggap dapat diubah, karena berasal dari perumusan bersama. Mereka menyetujui perubahan yang jujur dan disetujui bersama, serta merasa bertanggung jawab menaatinya. (3) Fase subyektif anak memperhatikan motif/kesengajaan dalam penilaian perilaku. Perkembangan moral dipengaruhi upaya membebaskan diri dari ketergantungan pada orang tua, meningkatkan interaksi dengan sesama dan berkontak dengan pandangan lain. Dengan interaksi yang bertambah

\footnotetext{
${ }^{4}$ digilib.uinsby.ac.id/19541/6/Bab\%202,pdf.
} 
luas anak makin mampu memahami pandangan orang lain dan berbagi aturan untuk kehidupan bermoral dalam kebersamaan.

Dalam kategori perkembangan moral, kohlberg (gunarsa, 1985) mengemukakan tiga tingkat dengan enam tahap perkembangan moral:

1. Tingkat 1: Prakonvensional

Pada tingkat ini aturan berisi aturan moral yang dibuat berdasarkan otoritas. Anak tidak melanggar aturan moral karena takut ancaman atau hukuman dari otoritas. Tingkat ini dibagi menjadi dua tahap: (1) tahap orientasi terhadap kepatuhan dan hukuman pada tahap ini anak hanya mengetahui bahwa aturan-aturan ini ditentukan oleh adanya kekuasaan yang tidak bisa diganggu gugat. Anak harus menurut, atau kalau tidak, akan mendapat hukuman, (2) tahap relativistik hedonosme pada tahap ini anak tidak lagi secara mutlak tergantung pada aturan yang berada di luar dirinya yang ditentukan orang lain yang memiliki otoritas. Anak mulai sadar bahwa setiap kejadian mempunyai beberapa segi yang bergantung pada kebutuhan (relativisme) dan kesenangan seseorang (hedonisme).

\section{Tingkat 2: Konvensional}

Pada tingkatan ini anak mematuhi aturan yang dibuat bersama agar diterima dalam kelompoknya. Tingkat ini juga terdiri dari dua tahap: (1) tahap orientasi mengenai anak yang baik. Pada tahap ini anak mulai memperlihatkan orientasi perbuatan yang dapat dinilai baik atau tidak baik oleh orang lain atau masyarakat. Sesuatu dikatakan baik dan benar apabila sikap dan perilakunya dapat diterima oleh orang lain atau masyarakat. (2) tahap mempertahankan norma sosial dan otoritas. Pada tahap ini anak menunjukkan perbuatan baik dan benar bukan hanya agar dapat diterima oleh lingkungan masyarakat di sekitarnya, tetapi juga bertujuan agar dapat ikut mempertahankan aturan dan norma/ nilai sosial yang ada sebagai kewajiban dan tanggung jawab moral untuk melaksanakan aturan yang ada. 
3. Tingkat 3: pasca konvensional.

Pada tingkat ini anak mematuhi aturan untuk menghindari hukuman kata hatinya. Tingkat ini juga terdiri dari dua tahap: (1) tahap orientasi terhadap perjanjian antara dirinya dengan lingkungan sosial. Pada tahap ini ada hubungan timbal balik antara dirinya dengan lingkungan sosial dan masyarakat. Seseorang menaati aturan sebagai kewajiban dan tanggung jawab dirinya dalam menjaga keserasian hidup masyarakat, (2) tahap universal. Pada tahap ini selain ada norma pribadi yang bersifat subyektif ada juga norma etik (baik/ buruk, benar/ salah) yang bersifat universal sebagai sumber menentukan sesuatu perbuatan yang berhubungan dengan moralitas. ${ }^{5}$

b. Faktor yang Mempengaruhi Perkembangan Moral

Faktor yang paling mempengaruhi penilaian moral adalah keluarga. Rice ( dalam Suciati, 2008) penelitian mengenai perkembangan moral anak dan remaja menekankan pentingnya peran orang tua dan keluarga. Terdapat beberapa faktor keluarga yang berhubungan secara signifikan dengan pembelajaran moral pada anak:

1) Tingkat kehangatan, penerimaan dan kepercayaan yang ditunjukan terhadap anak. Anak cenderung mengagumi dan meniru orangtua yang hangat, sehingga menumbuhkan sifat yang baik pada anak. Teori differential assosiation dari Sutherland dan Cressey (dalam Suciati, 2008) menjelaskan bahwa prioritas, durasi, intensitas dan frekuensi dari hubungan orangtua anak memfasilitasi pembelajaran moral dan perilaku kriminal pada anak. Hubungan orangtua anak yang dianggap penting (prioritas tinggi) dalam jangka waktu yang lama (durasi tinggi), dikarakteristikan dengan kedekatan emosi (intensitas tinggi) serta jumlah kontak dan komunikasi yang maksimal (frekuensi tinggi), memiliki efek positif pada perkembangan moral anak.

${ }^{5}$ Laila Maharani, Perkembangan Moral Pada Anak Moral Development in Children, Konseli: Jurnal Bimbingan dan Konseling 01 (2) (2014). 
2) Frekuensi interaksi dan komunikasi antara orangtua dan anak. Teori role modelling mengatakan bahawa identifikasi anak terhadap orangtua dipengaruhi frekuensi interaksi orangtuaanak. Orangtua yang sering berinteraksi secara intensif dengan anaknya cenderung lebih mempunyai pengaruh terhadap kehidupan anaknya. Interaksi orangtua-anak memberikan kesempatan untuk pembahasaan nilai-nilai dan normanorma, terutama bila interaksi dilakukan secara demokratis dan bersifat mutual.

3) Tipe dan tingkat disiplin yang dijalankan orangtua. Hasil penelitian menunjukan bahwa disiplin mempunyai efek yang positif terhadap pembelajaran moral ketika:

a. Konsisten, baik intraparent (konsisten dalam melakukan disiplin maupun interparent (konsisten antara kedua orangtua).

b. Kontrol terutama dilakukan secara verbal melalui penjelasan guna mengembangkan kontrol internal pada anak. Orangtua yang melakukan penjelasan verbal secara jelas dan resional menghasilkan internalisasi nilai dan standar pada anak, terutama ketika penjelasan disertai dengan afeksi sehingga anak cenderung untuk menerima. Remaja menginginkan dan membutuhkan arahan orangtua.

c. Adil dan sesuai serta menghindari kekerasan Orangtua yang menggunakan kekerasan menyimpang dari tujuan disiplin, yaitu, mengembangkan hati nurani, sosialisasi, dan kooperasi (Herzberger and Tennen, 1985, dalam Rice, 1993). Orangtua yang terlalu permisif juga menghambat perkembangan sosialisasi dan moral anak karena mereka tidak memberikan bantuan untuk mengembangkan control dalam diri anak.

d. Bersifat demokratis, bukan permisif ataupun autokratik.

4) Contoh yang diberikan orangtua bagi anak. Hasil penelitian menunjukan bahwa perilaku menyimpang ayah berkorelasi secara signifikan dengan perilaku devian anak pada masa remaja dan dewasa. Sangatlah penting 
bagi orangtua untuk menjadi sosok yang bermoral jika ingin memberikan model positif bagi anak mereka untuk ditiru.

5) Kesempatan untuk mendiri yang disediakan orangtua. ${ }^{6}$

\section{c. Perkembangan Spiritual}

Potensi yang ada pada setiap anak perlu digali oleh kedua orangtuanya agar mempunyai kecerdasan spiritual sejak usia dini. Jika keluarga dapat mengarahkan anaknya sejak usia dini agar melalui agama Islam, anak dibiasakan berzikir untuk mengingat Allah, doa, istighar, puasa, dan salat merupakan rangkaian ibadah yang dapat membentuk anak menjadi sehat mentalnya sejak usia dini.

Jika anak sejak usia dini sudah diberikan pemahaman untuk menumbuhkembangkan sifat-sifat terpuji (mahmudah) dan menghilangkan sifat-sifat tercela (mazmumah), akan didapatkan masa depan anak yang tidak membuat masalah bagi kedua orangtuanya. Keluarga sebagai pendamping anak pada saat anak berada di rumah akan membekali anak dengan jiwa yang sehat melalui agama yang berfungsi sebagai terapi bagi jiwa yang gelisah dan terganggu.

Potensi yang ada pada setiap anak perlu digali oleh kedua orangtuanya agar mempunyai kecerdasan spiritual sejak usia dini. Jika keluarga dapat mengarahkan anaknya sejak usia dini agar melalui agama Islam, anak dibiasakan berzikir untuk mengingat Allah, doa, istighar, puasa, dan salat merupakan rangkaian ibadah yang dapat membentuk anak menjadi sehat mentalnya sejak usia dini. Jika anak sejak usia dini sudah diberikan pemahaman untuk menumbuhkembangkan sifat-sifat terpuji (mahmudah) dan menghilangkan sifat-sifat tercela (mazmumah), akan didapatkan masa depan anak yang tidak membuat masalah bagi kedua orangtuanya. Keluarga sebagai pendamping anak pada saat anak berada di rumah akan membekali anak dengan jiwa yang sehat melalui agama yang berfungsi sebagai terapi bagi jiwa yang gelisah dan terganggu.

Spiritual dapat diartikan sebagai esensi yang hidup; penuh kebajikan;

\footnotetext{
${ }^{6}$ digilib.uinsby.ac.id/19541/6/Bab\%202.pdf.
} 
suatu ciri atau atribut kesadaran yang mencerminkan nilai-nilai kemanusiaan/being values. Dengan demikian kecerdasan spiritual adalah kemampuan memahami hubungan-hubungan kompleks yang didasarkan atas esensi yang hidup, kebajikan dan kesadaran yang mencerminkan nilainilai kemanusiaan. ${ }^{7}$

\section{Hasil Penelitian}

\section{a. Perkembangan Moral Santri}

Dari hasil observasi di lapangan dapat diketahui bahwa, perkembangan moral anak/santri pada madrasah diniyah al-Mutma'innah Winong Jetis adalah sebagai berikut:

1) Para santri madrasah mayoritas sudah berperilaku baik walaupun belum $100 \%$.

2) Setiap anak/santri madrasah memiliki karakteristik atau keunikan masing-masing dalam hal moral/tingkah laku.

3) Para santri madrasah mayoritas sudah berperilaku sopan santun, hormat kepada guru, walaupun belum maksimal karena karakter anak itu berbeda-beda.

4) Para santri sudah berperilaku baik kepada masyarakat sekitar, walaupun belum maksimal dan perlu bimbingan yang lebih baik lagi.

5) Para santri madrasah sudah berperilaku baik kepada teman sesamanya, walaupun belum $100 \%$.

6) Para santri madrasah sudah memiliki rasa tanggungjawab terhadap dirinya, guru dan sesama teman.

7) Para santri madrasah suka mencontoh segala apapun yang mereka lihat, amati, dan mereka dengar, baik dari guru, teman dan masyarakat sekitar.

b. Perkembangan Spiritual

Perkembangan spiritual anak/santri madrasah diniyah alMutma'innah adalah sebagai berikut:

${ }^{7}$ R.A. Anggraini Notosrijoedono, Peran Keluarga Dalam Mengembangkan Kecerdasan Spiritual Anak Usia Dini, MIQOT Vol. XXXVII No. 1 Januari-Juni 2013. 
1) Para santri sudah mulai mengenal jati dirinya sebagai hamba Allah SWT, meyakini adanya Tuhan Sang Pencipta, Malaikat, Rasul, dan kitab Allah.

2) Para santri sudah mulai mengenal jati dirinya sebagai santri yang belajar agama Islam di madrasah.

3) Para santri sudah mulai mempraktekkan ibadah-ibadah seperti sholat berjamaah, mengaji, berwudlu, berdo'a, berpuasa dan lain-lain, baik di madrasah maupun di masyarakat/tempat tinggal.

4) Para santri memiliki sikap antusias dan semangat dalam belajar alQur'an meliputi tartilnya, hafalan dan tajwid.

5) Para santri memiliki semangat yang tinggi dalam belajar, berkreatifitas, berpetualang di luar dan lain-lain.

c. Faktor Yang Mempengaruhi Perkembangan Moral dan Spiritual

Ada banyak faktor yang bisa mempengaruhi perkembangan anak khususnya perkembangan moral dan spiritual. di antara faktor tersebut adalah: faktor intern dan faktor ekstern. Faktor intern yaitu dari pribadi anak itu sendiri. Kepribadian anak yang sulit berkembang tentunya berpengaruh terhadap perkembangan moral dan spiritualnya, walaupun sudah ada upaya pendidikan dan bimbingan yang maksimal dari guru dan orang tua maupun masyarakat. Semua itu terjadi karena kembali kepada fitrah anak yaitu memiliki karakteristik yang berbeda-beda.

Sedangkan faktor ekstern (lingkungan) meliputi hal-hal berikut:

1) Keluarga

Keluarga adalah tepat belajar pertama dan utama bagi setiap anak, yang menjadi modal dasar dalam keberhasilan proses perkembangan kepribadian anak. Kedua orangtua berperan sangat penting dalam mencetak pribadi-pribadi yang sholeh dan sholehah, di samping guru sebagai pelaksana di masyarakat, tapi tetap orangtua lah faktor yang paling penting dan dominan bagi perkembangan moral dan spiritual anak. 
Keluarga yang bisa memberikan contoh yang baik, tentu akan berpengaruh baik bagi perkembangan kepribadian anak. Sebaliknya, bila keluarga tidak bisa memebrikan contoh yang baik, maka sangat mustahil kepribadian anak yang baik akan terbentuk. Anak pada dasarnya meniru apa yang mereka lihat, amati dan mereka dengar dari sekitarnya.

2) Guru

Guru adalah seorang figur yang selayaknya untuk diteladani, segala tindak tanduknya akan selalu menjadi sorotan masyarakat terutama anak. Dalam hal ini tugas guru adalah membantu para orang tua untuk mendidik putra putrinya, mengembangkan kepribadian yang sholeh dan sholehah, demi terciptanya masyarakat yang berkepribadian luhur dan berakhlakul karimah. Guru yang mampu menjadi teladan yang baik akan berpengaruh terhadap perkembangan moral dan spiritual santri. Seperti kata pepatah "Guru itu digugu dan ditiru", yang maknanya guru itu dipatuhi dan diikuti/dicontoh.

\section{3) Teman Sebaya}

Anak-anak dalam bergaul dengan sesamanya sangat dominan pula dalam hal mencontoh dan meniru segala tindakannya baik yang positif maupun yang negatif. Dalam bersosialisasi dengan teman sebaya, anak mulai belajar hal-hal apa saja yang belum didapatkan dalam keluarga, seperti persaingan, kerjasama, saling menghargai dan lain sebagainya.

Teman yang baik akan berpengaruh terhadap perkembangan moral dan spiritual yang baik, demikian juga sebaliknya teman yang kurang baik bisa juga memberi dampak buruk pada temannya yang lain, karena kerusakan budi pekerti itu menular. 


\section{PENUTUP}

\section{Kesimpulan}

a. Perkembangan moral anak/santri pada madrasah diniyah al-Mutma'innah Winong Jetis adalah sebagai berikut: anak/santri berperilaku baik walaupun belum $100 \%$, memiliki karakteristik atau keunikan masingmasing dalam hal moral/tingkah laku, berperilaku sopan santun, hormat kepada guru, berperilaku baik kepada masyarakat sekitar, walaupun belum maksimal dan perlu bimbingan yang lebih baik lagi, berperilaku baik kepada teman sesamanya, memiliki rasa tanggungjawab terhadap dirinya, guru dan sesama teman, suka mencontoh segala apapun yang mereka lihat, amati, dan mereka dengar, baik dari guru, teman dan masyarakat sekitar.

b. Perkembangan Spiritual

Perkembangan spiritual anak/santri madrasah diniyah alMutma'innah adalah sebagai berikut: Para santri sudah mulai mengenal jati dirinya sebagai hamba Allah SWT, meyakini adanya Tuhan Sang Pencipta, Malaikat, Rasul, dan kitab Allah, sudah mulai mengenal jati dirinya sebagai santri yang belajar agama Islam di madrasah, mulai mempraktekkan ibadah-ibadah, santri memiliki sikap antusias dan semangat dalam belajar al-Qur'an meliputi tartilnya, hafalan dan tajwid, memiliki semangat yang tinggi dalam belajar, berkreatifitas, berpetualang di luar dan lain-lain.

c. Faktor yang mempengaruhi perkembangan moral dan spiritual adalah: faktor intern dan faktor ekstern.

\section{Saran dan Kritik}

Kepada seluruh pembaca artikel di atas, mohon kritik dan masukannya demi tercapainya penulisan artikel yang baik. Apabila masih banyak kekurangan dalam penulisan artikel di atas, mohon maaf yang sebesar-besarnya. Jaazakumullah khairan kathiran. 


\section{DAFTAR PUSTAKA}

digilib.uinsby.ac.id/19541/6/Bab\%202.pdf.

eprint.walisongo.ac.id/7074/3/BAB\%2011.pdf.

Maharani, Laili. Perkembangan Moral Pada Anak Moral Development in Children, Konseli: Jurnal Bimbingan dan Konseling 01 (2) (2014).

Nurjanah, Siti. Perkembangan Nilai Agama dan Moral (STTPA Tercapai), Jurnal Paramurobi, Vol. 1, No. 1, Januari-Juni 2018. 